\title{
Profile of Children with HIV in an Anti-Retroviral Therapy (ART) Clinic of Western Nepal
}

\author{
Ghimire JJ', Chapagain $\mathrm{RH}^{2}$, Shrestha SK ${ }^{3}$ Bastola RC ${ }^{4}$
}

\begin{abstract}
Introduction: HIV in children is a public health problem in a developing country like Nepal. The aim of the study was to determine the clinical, nutritional and immunological profile of HIV + ve children enrolled in the ART clinic of Pokhara Academy of Health Sciences (PAHS). Materials and Method: This was a retrospective study of children enrolled in the ART clinic over a period of 10 years from July 2007 to June 2017. Clinical characters, Nutritional status and immunological status of children enrolled in the ART clinic were noted in the predesigned pro forma from the record of the clinic and review of the chart of the patients. Results: One hundred twelve children were enrolled in the Clinic during the study duration. Out of them 57 were males and 55 were females. All the children acquired infection through mother to child transmission. Majority of them from age group 1 to 5 years at the time of presentation. Fortysix percent were in the clinical stage III. The median CD4 count was 283.Fifty percent of the children were undernourished. Most of the children were started on AZT/3TC/NVP as first line ART. Conclusion: Although perinatal route was the most common route of transmission of HIV in children, diagnosis was late in the age group of 1-5 years and most of them were diagnosed in the advanced stage of HIV with Low CD4 count.
\end{abstract}

Key words: HIV in children, Antiretroviral Therapy

\section{Introduction}

$\mathrm{H}^{2}$ $V$ in children have been an important public health problem¹. Globally there are 2.1 million children living with HIV ${ }^{1}$.Of them $43 \%$ are receiving life-saving antiretroviral therapy (ART) ${ }^{1}$. Children account for about 6 per cent of all people living with HIV, nine per cent of new HIV infections and $11 \%$ of all AIDS-related deaths ${ }^{1,2}$. In 2016, 160,000 children were newly infected with HIV, mainly through transmission of the virus from their mothers during pregnancy, delivery or while breastfeeding ${ }^{1,2}$. Evidence shows that early initiation of antiretroviral drugs in infants with HIV can save lives ${ }^{3}$.The number of paediatric HIV cases continues to rise due to high prevalence of HIV infection in mother and failure of adoption of appropriate measures in the prevention of perinatal transmission ${ }^{3}$. In Nepal there are approximately 1600 children living with HIV4-5. However with the effective use of ART in children there has been decrease
${ }^{1}$ Dr. Jagat Jeevan Ghimire, MBBS, MD, Consultant Paediatrician, Pokhara Academy of Health Sciences(PAHS), ${ }^{2} \mathrm{Dr}$. Ram HariChapagain, MBBS, MD, Assistant Professor National Academy of Medical Sciences (NAMS)/Senior Consultant Paediatrician, Kanti Children's Hospital, ${ }^{3} \mathrm{Dr}$. Shree Krishna Shrestha, MBBS, MD Chief Consultant Paediatrician and Head of the Department of Paediatrics, Pokhara Academy of Health Sciences (PAHS), ${ }^{4}$ Dr. Ram Chandra Bastola, MBBS, MD, Consultant Pediatrician, Pokhara Academy of Health Sciences (PAHS).

\section{Address for correspondence \\ Dr Jagat Jeevan Ghimire \\ Consultant Pediatrician \\ Pokhara Academy of Health Sciences (PAHS) \\ Tel No; +9779851136443 \\ E-mail:jagat_ghimire@yahoo.com}

\section{Acknowledgements: None \\ Funding: Nil \\ Conflict of Interest: None \\ Permission from IRB: Yes}

\section{How to cite}

Ghimire JJ, Chapagain RH, Shrestha SK Bastola RC. Profile of Children with HIV in an Anti-Retroviral Therapy (ART) Clinic of Western Nepal. J Nepal Paediatr Soc 2017;37(2):164167.

doi: http://dx.doi.org/10.3126/jnps.v37i2.18636

This work is licensed under a Creative Commons Attribution 3.0 License. 
in the progression to AIDS and mortality ${ }^{6,7}$. The aims of the study were to find out the demographic profile as well as the modes of transmission, clinical stage during diagnosis, immunological status as indicated by CD4 count,nutritional status and status of TB infection amongst children with HIV infection.

\section{Material and Methods}

This was a retrospective study done using the hospital record and charts of the children who are registered in the ART clinic of Pokhara academy of health sciences, over a period of 10 years from Shrawan 2064 (July 2007)to Asar 2074(June 2017). Age, sex, occupation of mother, clinical stage, nutritional status and CD4 at diagnosis was noted. Clinical stage was done using $\mathrm{WHO}$ clinical staging ${ }^{8}$. Nutritional status was assessed using WHO growth charts and classified using WHO classification ${ }^{9}$. The initial regimen of Anti-retroviral therapy(ART), Second line ART(if used) along with indication for change in regimen was noted. Approval for the study was taken from the hospital administration. Data was recorded using Microsoft excel and analysed using SPSS 22.

\section{Results}

There were 112 children and adolescent enrolled in the ART clinic of the hospital. Out of them 57 were males and 55 were females with $M: F$ ratio of 1.1:1. Majority of them from age group 1 to 5 years at the time of presentation. The median age of patients enrolled in the study was 13 years. Eighty-two percent of mothers and $75 \%$ of fathers were receiving ART at the time of presentation.All the mothers of the children were housewife by profession. All children acquired infection by mother to child transmission. Fifty-two percent of our children were undernourished. Forty-six \% were in the clinical stage III, 25\% were in clinical stage IV and 24\% were in clinical stage II. TB HIV co-infection was noted in one case. The median CD4 of the patients was 283. Twenty nine percent of our children had CD4 counts below 200. Hundred children were started on AZT/TC/ NVP as first line ART. Six were started on AZT/3TC/EFV, four were started on TDF/3TC/NVP as first line ART and one was started on stavudine containing regimen. Forty children had their regimen switched to another regimen for immunological and/or virological failure.

\section{Discussion}

HIV in children has been a challenge to global health ${ }^{3}$.Moreover the increased case load in the poorest part of the world adds further difficulties in the management ${ }^{6}$. Mother to child transmission of HIV infection is the most common infection in developing countries like Nepal. Lack of proper ANC care and lack of ART during pregnancy have been important reasons for mother to child transmission of HIV in children ${ }^{4,8}$. All children enrolled in our clinic got infected by 'mother to child transmission' which shares similarities with the global and national level data on transmission of HIV in children ${ }^{4}$.This finding is comparable to finding of the studies done in India and Nepal with all of the enrolled children acquiring infection by mother to child transmission with all of enrolled patients infected by mother to child transmission ${ }^{6,10}$.

Our study showed delay in diagnosis of HIV in children as most of children were in the age group 1-5 years during diagnosis. This shares similarities with the other studies done in India and Nepal by Madhivan etal, Gomber et al and Poudel et al with median age of 58 months, 4.0 years and 6.24 years respectively $6,7,11$. These findings suggest there is delay in diagnosis of HIV in children in the region.

Table 1: Showing study characters of children with HIV

\begin{tabular}{|c|c|c|c|}
\hline \multicolumn{2}{|l|}{ Character } & Number (n) & Percentage (\%) \\
\hline \multicolumn{2}{|c|}{ Mother under ART at presentation } & 92 & 82 \\
\hline \multicolumn{2}{|c|}{ Mother under ART currently } & 85 & 75 \\
\hline \multicolumn{2}{|c|}{ Father receiving ART currently } & 85 & 75 \\
\hline \multicolumn{2}{|c|}{ Mother's profession } & Homemaker & 100 \\
\hline \multirow{4}{*}{ Age at diagnosis } & $<1 \mathrm{yr}$ & 0 & 0 \\
\hline & $1-5 \mathrm{yr}$ & 50 & 44 \\
\hline & $5-10$ & 40 & 36 \\
\hline & $>10$ & 22 & 20 \\
\hline \multirow{4}{*}{$\begin{array}{l}\text { Clinical stage at } \\
\text { presentation }\end{array}$} & I & 5 & 5 \\
\hline & II & 27 & 24 \\
\hline & III & 52 & 46 \\
\hline & IV & 28 & 25 \\
\hline \multicolumn{2}{|c|}{$\begin{array}{l}1^{\text {st }} \text { line ART regimen } \\
\text { (zidovudine)/(lamivudine)/Nevirapine) }\end{array}$} & 54 & 48 \\
\hline
\end{tabular}


Our study showed $52 \%$ of children being undernourished. Undernutrition is an important sign of HIV infection in children ${ }^{12}$. It also shows severity of HIV infection as poor nutritional status signifies higher clinical stage which in turn reflects poor prognosis ${ }^{8}$. Improvement in nutritional status is associated with improved outcome ${ }^{12}$.A study done byPoudelet.al. in eastern Nepal showed $54 \%$ of HIV infected children being undernourished ${ }^{6}$. Different studies done in Northern India by Ravi Ambey et al and Kapavarapu et al showed $60 \%$ and $72 \%$ respectively ${ }^{12,13}$. So the finding of our studies were comparable to these studies in relation to nutritional status ${ }^{6,12,13}$.The poor nutritional status of the children showed more focus is needed in nutritional assessment and management of these children.

Tuberculosis is the most common opportunistic infection in HIV children ${ }^{4}$.Well studied epidemiological and biological features between HIV and TB influence the distribution, progression and outcomes of both ${ }^{14}$. HIV is an important risk factor for the development of TB and the HIV epidemic is a key factor behind the resurgence in $\mathrm{TB}^{15,16}$.TB in HIV infected individual represent One in eight incident cases of $\mathrm{TB}^{15}$. Tuberculosis signifies higher clinical stage of HIV infection and TB in an HIV infected child is considered to be a clinical indication for initiation of antiretroviral treatment ${ }^{17}$. However the ever challenging diagnosis of TB in children is complicated by altered immune response in HIV infected children ${ }^{14}$. Only one child in our study had diagnosis of TB. The prevalence of TB among HIV infected children in different studies ranged from $16 \%$ to $52 \%{ }^{18-21}$.Our study differed from these studies in regards to TB infection.

\section{References}

1. Children \& AIDS: 2015 Statistical Update - UNICEF DATA [Internet]. UNICEF DATA. 2018 [cited 4 February 2018]. Available from: https://data.unicef.org/ resources/children-aids-2015-statistical-update-2/.

2. Progress report 2011: Global HIVIAIDS response [Internet]. World Health Organization. 2011 [cited 4 February 2018]. Available from: http://www.who.int/hiv/ pub/progress_report2011/en/

3. Kaul, D. \& Patel, J.A.Clinical manifestations and management of pediatric HIV infection. Indian J Pediat 2001;68(7):623-31.DOI: https://doi.org/10.1007/ BF0275227

4. National consolidated guidelines for treating and preventing HIV infection [Internet]. Saarctb.org. 2014 [cited 4 February 2018]. Available from: http:// saarctb.org/new/wp-content/uploads/2016/03/NepalNational_Consolidated_Guideline_For_Treating_and_ Preventing_HIV_in_Nepal.pdf
This may be due to low screening for TB in children enrolled in our study.

Clinical stage as defined by $\mathrm{WHO}$ is an important assessment of severity of HIV infection ${ }^{8}$. Higher clinical stage signify severe infection and need of $A R T^{6,8}$. In different studies done in Nepal and Indiashowed most of the children were in the clinical stage 1 at diagnosis $\mathrm{s}^{6,11}$. Most of our children were at who clinical Stage-3 at diagnosis which was comparable to the study done by Chapagain et $\mathrm{al}^{22}$.The higher clinical stage at diagnosis signifies delay in the diagnosis.CD4 cells which remain as important part of immune response against viruses like HIV are important part of assessment of HIV infection ${ }^{23}$.Decrease in CD4 not only signifies severity of infection but also indicate need of treatment and response to treatment ${ }^{23,24}$.In different studies done in India and Nepal the median CD4 were 543 and 298 respectively ${ }^{6,7}$.The finding of our study was comparable to these results with median CD4 value of 284 and $29 \%$ of our children showing severe immunosuppression with CD4 below 200. Higher clinical stage at presentation and severe immunosuppression indicated delay in diagnosis. These finding also point towards lack of adherence of Prevention of Mother to Childhood Transmission (PMTCT) program.

\section{Conclusion}

Although perinatal route was the most common route of transmission of HIV, diagnosis was late and most of them were diagnosed in the advanced clinical stage with low CD4 count. Undernutrition was common among HIV infected children.

5. Children(0-14) living with HIV 2015 [Internet]. 2015 [cited 4 February 2018]. Available from: https://data. worldbank.org/indicator/SH.HIV.0014.

6. Prakash Poudel RP, Mohit Chitlangia, Shipra Chaudhary. Profile of HIV infected children: A hospital based study at Eastern Nepal Asian. Pacific J Trop Dis 2014;4(3):169-75 DOI: 10.1016/S22221808(14)60499-0

7. Madhivanan $\mathrm{P}$ MS, Kumarasamy N, Yepthomi $\mathrm{T}$, Venkatesan C, Lambert JS, et al.Clinical manifestations of HIV infected children. Indian $J$ Pediatr 2003;70(8):615-20.

8. Consolidated guidelines on the use of antiretroviral drugs for treating and preventing HIV infection [Internet]. World Health Organization. 2016 [cited 4 February 2018]. Available from: http://www.who.int/hiv/ pub/arv/arv-2016/en/

9. Multicentre Growth Reference Study Group. WHO child growth standards: length/ height-for-age, weightfor-age, weight-for-length, weight-for height and 
body mass indexfor-age: methods and development. [Internet]. 2006 [cited 4 February 2018]. Available from: http://www.who. int/childgrowth/standards/ technical_report/en/index.html.

10. Rakesh Lodha, Tanu Singhal,Yogesh Jain, Kabra SKS, $P$ Vimlesh Seth.Pediatric HIV infection in a tertiary care center in North India: early impressions. Indian Pediatr 2000;37(9):982-6.

11. Gomber S KJ, Chandra J, Anand R.Profile of HIV infected children from Delhi and their response to antiretroviral treatment.Indian Pediatr2011;48:703. DOI: https://doi.org/10.1007/s13312-011-0117-7

12. Ambey R SS, Sharma A GR, Goyal B. Assessment of nutritional status of HIV positive children inART centre a study from central India. Int $J$ Pediatr Res Pract 2015;1(1):7-11

13. Kapavarapu PK BO, Perumpil M, Duggan C, Dinakar C, Krishnamurthy S. Growth patterns and anaemia status of HIVinfectedchildren living in an institutional facility in India. Trop Med IntHealth 2012;17:962-71. DOI:10.1111/j.1365-3156.2012.03022.x

14. Venturini E, Turkova A, Chiappini E, Galli L, de Martino M, Thorne C. Tuberculosis and HIV coinfection in children. BMC Infect Dis 2014;08;14(1):S5. DOI:10.1186/1471-2334-14-S1-S5

15. Time to act. Save a million lives by 2015. Prevent and treat tuberculosis among people living withHIV WHO. [cited 4 February 2018].http://www.who.int/tb/ challenges/hiv/tbhiv_brochure_singles.pdf

16. UNAIDS report on the global AIDS epidemic 2013 UNAIDS[cited 4 February 2018].[http://www.unaids. org/en/media/unaids/contentassets/documents/ epidemiology/2013/gr2013/UNAIDS_Global_ Report 2013 en.pdf].
17. Global update on HIV treatment 2013: results, impacts and opportunities. World health Organisation[cited 4 February 2018].[http://apps.who.int/iris/ bitstream/10665/85326/1/9789241505734_eng.pdf]

18. Luo C CC, Bhat G, Raviglione M, Diwan V, DuPont $\mathrm{HL}$, Zumla A. Human immunodeficiency virus type1 infection in Zambian children with tuberculosis: changing seroprevalence and evaluation of a thioacetazone-free regimen. Tuber Lung Dis 1994;75:110-5.

19. Fairlie L BN, Reubenson G, Moore DP, Madhi SA. High prevalence of childhood multi-drug resistant tuberculosis in Johannesburg, South Africa: a cross sectional study. BMC Infect Dis 2011;11:10-28.

20. Karande $S$, Bhalke S, Kelkar A, Ahuja S, Kulkarni M, Mathur M. Utility of clinically-directed selective screening to diagnose HIV infection in hospitalized children in Bombay, India. J Trop Pediatr 2002;48:14955.

21. Matos TP, Kritski AL, Ruffino Netto A. Epidemiological aspects of tuberculosis in children and adolescents in Rio de Janeiro. J Pediatr (Rio J) 2012;88(4):335-40.

22. Chapagain RH, Kamar SB, Singh DR. Retrospective study of HIV infection in Anti Retroviral Treatment center of Mahendranagar, Nepal. Kathmandu Univ Med J 2016;53(1):54-7.

23. Hoffman J vGJ, Colebunders R, McKellar M. Role of the CD4 count in HIV management. HIV Ther 2010. HIV Ther 2010;4(1):27-39.

24. Sharma S DG, Pokhrel BM, Rijal BP.Opportunistic infections in relation to CD4 level among HIV seropositive patients from central Nepal. Nepal Med Coll J2010;12(1):1-4 